\title{
A New Soil Moisture Retrieval Algorithm from the L-Band Passive Microwave Brightness Temperature Based on the Change Detection Principle
}

\author{
Xingming Zheng ${ }^{1,2}$, Zhuangzhuang Feng ${ }^{3}$, Hongxin $\mathrm{Xu}^{4}$, Yanlong Sun ${ }^{4}, \mathrm{Lei}^{\mathrm{Li}}{ }^{3}$, Bingze $\mathrm{Li}^{5}$, \\ Tao Jiang ${ }^{1}$, Xiaojie $\mathrm{Li}^{1}{ }^{1}$ and Xiaofeng $\mathrm{Li}^{1, *}$ \\ 1 Northeast Institute of Geography and Agroecology, Chinese Academy of Sciences, Changchun 130102, \\ China; zhengxingming@iga.ac.cn (X.Z.); jiangtao@iga.ac.cn (T.J.); lixiaojie@iga.ac.cn (X.L.) \\ 2 Changchun Jingyuetan Remote Sensing Test Site, Changchun 130102, China \\ 3 College of Resources and Environment, University of Chinses Academy of Sciences, Beijing 100049, China; \\ fengzhuangzhuang19@mails.ucas.ac.cn (Z.F.); lilei@iga.ac.cn (L.L.) \\ 4 Shanghai Aerospace Electronic Technology Institute, Shanghai 201109, China; \\ xuhongxin@804.sast.casc (H.X.); sunyanlong@804.sast.casc (Y.S.) \\ 5 School of Geomatics and Prospecing Engineering, Jilin Jianzhu University, Changhcun 130118, China; \\ libingze@jlju.edu.cn \\ * Correspondence: lixiaofeng@iga.ac.cn; Tel.: +86-0431-8554-2227
}

Received: 25 March 2020; Accepted: 17 April 2020; Published: 20 April 2020

check for updates

\begin{abstract}
The launch of the SMOS (Soil Moisture and Ocean Salinity) and SMAP (Soil Moisture Active Passive) satellites has led to the development of a series of L-band soil moisture retrieval algorithms. In these algorithms, many input parameters (such as leaf area index and soil texture) and empirical coefficients (such as roughness coefficient $\left(h_{\mathrm{P}}, N_{\mathrm{RP}}\right)$ and crop structure parameter $\left.\left(b_{\mathrm{P}}, t t_{\mathrm{P}}\right)\right)$ are needed to calculate surface soil moisture (SSM) from microwave brightness temperature. Many previous studies have focused on how to determine the value of these coefficients and input parameters. Nevertheless, it can be difficult to obtain their 'real' values with low uncertainty across large spatial scales. To avoid this problem, a passive microwave remote sensing SSM inversion algorithm based on the principle of change detection was proposed and tested using theoretical simulation and a field SSM dataset for an agricultural area in northeastern China. This algorithm was initially used to estimate SSM for radar remote sensing. First, theoretical simulation results were used to confirm the linear relationship between the change rates for SSM and surface emissivity, for both $\mathrm{H}$ and V polarization. This demonstrated the reliability of the change detection algorithm. Second, minimum emissivity (or the difference between maximum emissivity and minimum emissivity) was modeled with a linear relationship between vegetation water content, derived from a three-year (2016-2018) SMAP L3 SSM dataset. Third, SSM values estimated by the change detection algorithm were in good agreement with SMAP L3 SSM and field SSM, with RMSE values ranging from $0.015 \sim 0.031 \mathrm{~cm}^{3} / \mathrm{cm}^{3}$ and $0.038 \sim 0.051 \mathrm{~cm}^{3} / \mathrm{cm}^{3}$, respectively. The $\mathrm{V}$ polarization SSM accuracy was higher than $\mathrm{H}$ polarization and combined $\mathrm{H}$ and $\mathrm{V}$ polarization accuracy. The retrieved SSM error from the change detection algorithm was similar to SMAP SSM due to errors inherited from the training dataset. The SSM algorithm proposed here is simple in form, has fewer input parameters, and avoids the uncertainty of input parameters. It is very suitable for global applications and will provide a new algorithm option for SSM estimation from microwave brightness temperature.
\end{abstract}

Keywords: soil moisture; passive microwave remote sensing; change detection; farmland 


\section{Introduction}

Surface soil moisture (SSM) plays an important role in governing water and energy cycles at the land-atmosphere boundary. Estimation of SSM using remote sensing methods has become a key component of observation and research programs (e.g., the Global Energy and Water Cycle Experiment (GWEWX), the Integrated Global Water Cycle Observation (IGWCO), and the Global Soil Wetness Project (GSWP)) [1,2]. In addition, accurate SSM monitoring and prediction play a crucial role in research on crop growth status, predicting flood and drought events, hydrology research, and global change research [3-5].

Due to its strong penetration ability and sensitivity to SSM [6], microwave remote sensing technology has become the primary method for SSM estimation. From the early SMMR (Scanning Multichannel Microwave Radiometer), SSMI (Special Sensor Microwave/Imager), AMSR-E (Advanced Microwave Scanning Radiometer for EOS), AMSR2 (Advanced Microwave Scanning Radiometer 2) and FY (Fengyun) series of satellite-based passive microwave radiometers, to more recent SMOS (Soil Moisture and Ocean Salinity), Aquarius and SMAP (Soil Moisture Active Passive) sensors, one of the goals of these satellite missions is to obtain global SSM. Due to the difference in observation frequencies and the forward simulation model, many SSM algorithms have been developed based on physical and empirical principles. It is confirmed that L-band is the best band for estimating SSM in existing satellites. Thus, we briefly review parts of these L-band SSM inversion algorithms in the following part.

These algorithms include SMOS L2/L3, SMAP L2, the dual channel algorithm (DCA), the land parameter retrieval model (LPRM), multi-orbit retrievals of soil moisture and optical depth (MT-DCA) and other algorithms (such as the explicit radiative transfer model and methods based on neural networks or local regressions) [7]. Although they have produced good SSM estimation results, the whole estimation process is still relatively complex and requires a lot of input parameters, which are also difficult to measure and obtain (such as effective scattering albedo, soil texture, etc.). Therefore, these algorithms also have some limitations: 1) Due to different data sources and processing methods, input parameters may have different uncertainties in different regions of the world, which are difficult to evaluate quantitatively; 2) Parameters are heterogeneous within a microwave pixel but are considered as homogeneous pixels in the SSM inversion process; 3 ) Some parameters (such as effective scattering albedo, vegetation structure parameters $\left(\mathrm{tt}_{\mathrm{H}}\right.$ and $\left.\mathrm{tt}_{\mathrm{V}}\right)$, and roughness parameters $\left(\mathrm{NR}_{\mathrm{V}}\right.$ and $\left.\mathrm{NR}_{\mathrm{H}}\right)$ ) need to be assumed to be constant under certain circumstances (such as land cover type or vegetation type), and many previous studies have determined how these parameters are quantified.

Integrating the existing problems and the research basis for soil moisture algorithms, we hope to use change detection to develop an SSM estimation method based on microwave brightness temperature. The change detection algorithm idea was first proposed by Wagner et al. (1999) [8], who used it to estimate temporal SSM with ERS-1 and ERS-2 scatterometer data cycles. The core idea of this algorithm is a linear relationship between SSM change and the change in the backscatter coefficient, which is affected by vegetation characteristics. NDVI (Normalized Difference Vegetation Index) is generally used to represent the vegetation canopy influence $[9,10]$. The algorithm's feasibility has been verified through soil moisture estimation by radar remote sensing. Its advantage lies in its simplicity, which directly links the radar backscatter coefficient change with SSM change and reduces the impact of input parameter uncertainty. The disadvantage is that the minimum backscatter coefficient is somewhat related to surface roughness, which changes over time on an agricultural soil surface. Therefore, the algorithm is more suitable for grassland or shrub cover with constant (or slowly changing) roughness.

Given the limitations of existing SSM algorithms and the advantages of the change detection algorithm, this study discusses and analyzes the applicability of the change detection algorithm for estimating SSM from passive microwave brightness temperature. The algorithm was first analyzed from the physical perspective (physical model). Second, SSM, surface temperature and vegetation water content (VWC) datasets provided by SMAP were used to calculate the minimum (or maximum) of land surface emissivity and the minimum (or maximum) SSM used in the algorithm. Then, estimated 
SSM validation was carried out by in situ SSM, and finally, the advantages and disadvantages of the algorithm were analyzed along with its application potential.

\section{Data and Methods}

\subsection{Study Area and in Situ SSM}

The study area was located in the agricultural area of Dehui County $\left(125^{\circ} 14^{\prime} \sim 126^{\circ} 24^{\prime} \mathrm{E}\right.$, $44^{\circ} 02^{\prime} \sim 44^{\circ} 53^{\prime} \mathrm{N}$ ), Jilin Province, China (Figure 1). Annual average temperature and precipitation are $4.4^{\circ} \mathrm{C}$ and $520 \mathrm{~mm}$, respectively. This area has a mid-temperate zone and a continental monsoon climate with four distinct seasons. SSM varies greatly across the seasons, a condition that is very suitable for the development and validation of the soil moisture algorithm [11]. This area belongs to China's main grain production area and black soil belt, so it is mainly used for agricultural development. Therefore, crop type heterogeneity within a microwave pixel is low and the proportion of farmland is greater than $90 \%$.



Figure 1. Location of the study area and field soil moisture observation nodes.

In this area, a dense soil moisture observation network, with an area of $36 \times 36 \mathrm{~km}$, was established to provide the ground-based SSM dataset by 28 METER EC- 5 soil moisture sensors (Figure 1). To reduce the impacts of agricultural activities and the soil freeze-thaw cycle on observation data quality, the soil moisture sensors only collect data from May to September each year. In May (after sowing), all soil moisture nodes are installed in the field. At the end of September (before harvesting), they are taken back to the laboratory for calibration to ensure data quality. Three years of the ground-based SSM dataset (2016-2018) are used in this study. Although the soil texture (clay: 11.5\% 12.5\%, sand: $51.5 \% \sim 60.6 \%$ ), topography (average slope $<4.5^{\circ}$ ), and land cover (percent of farmland $>90 \%$ ) in this area are all relatively homogeneous, to obtain high-quality SSM at the passive microwave pixel scale, the Thiessen polygon method was used to convert point-scale soil moisture to pixel-scale [12].

\subsection{SMAP L3 SSM Dataset}

The SMAP L3 Radiometer Global Daily 36 km EASE-Grid Soil Moisture Product provides a composite of daily global land surface condition estimates retrieved by the SMAP passive microwave radiometer. Surface soil moisture (SMAP L3 SSM), surface temperature $\left(T_{S}\right)$, corrected L-band brightness temperature (TB), and vegetation water content (VWC) from the SMAP L3 SSM dataset were used in this study with a global, cylindrical $36 \mathrm{~km}$ Equal-Area Scalable Earth Grid (EASE-Grid 2.0) [13]. SMAP L3 SSM reflects soil water content change at soil depths of $0 \sim 5 \mathrm{~cm}$ estimated from SMAP TB. SMAP TB represents the weighted average of SMAP Level-1B brightness temperatures, whose 
boresights fall within each $36 \mathrm{~km}$ EASE-Grid 2.0 grid cell. SMAP $T_{\mathrm{S}}$ is the effective soil temperature, the weighted value of surface soil temperature ( $\left.T_{\text {surf }}\right)$ and deep soil temperature $\left(T_{\text {deep }}\right) \cdot T_{\text {surf }}$ refers to the average soil temperature for the first soil layer $(0-10 \mathrm{~cm})$ and $T_{\text {deep }}$ refers to the average soil temperature for the second soil layer $(10-20 \mathrm{~cm})$ in the GMAO GEOS-5 land surface model. The SMAP VWC is derived from $1 \mathrm{~km}$ MODIS NDVI data. Only one VWC is provided in the SMAP L3 dataset, but both ascending (6:00 p.m.) and descending (6:00 a.m.) orbital data are provided for $T_{\mathrm{S}}, \mathrm{SSM}$, and TB [14].

\subsection{Change Detection Algorithm}

\subsubsection{Microwave Emission Model}

A simple zero-order radiation transfer approach $(\tau-\omega)$ was used to simulate the L-band brightness temperature of vegetated soil, which has been used for retrieving SSM and modeling brightness temperature by many researchers [15-19]. The $\tau-\omega$ model is applicable for frequencies less than $\sim 5 \mathrm{GHz}$ [20], and is therefore appropriate for simulating L-band emissions. The $\tau-\omega$ model is expressed as follows [19]:

$$
T_{b}=T_{\mathrm{a}}^{\mathrm{up}}+t_{\mathrm{a}}\left[(1-\omega)\left(1-t_{\mathrm{v}}\right) T_{\mathrm{C}}+(1-\omega)\left(1-t_{\mathrm{v}}\right) T_{\mathrm{C}} R_{\mathrm{s}} t_{\mathrm{v}}+\left(1-R_{\mathrm{s}}\right) T_{\mathrm{s}} t_{\mathrm{v}}\right]
$$

where $T_{\mathrm{b}}$ is the simulated brightness temperature $(K), \mathrm{T}_{\mathrm{a}}^{\text {up }}$ represents upwelling atmospheric emissions, $\omega$ is the single scattering albedo of the canopy, $t_{\mathrm{a}}$ and $t_{\mathrm{v}}$ are atmospheric and canopy transmissivities, respectively, $T_{\mathrm{S}}$ and $T_{\mathrm{C}}$ are the effective soil and canopy temperatures, respectively $(\mathrm{K})$, and $R_{\mathrm{S}}$ is the reflectivity of the rough soil surface.

The atmospheric effect was ignored in this study due to its relatively high transparency in the L-band [21,22]. In satellite SSM retrieval, canopy temperature $\left(T_{V}\right)$ is usually assumed to be equal to soil temperature $\left(T_{\mathrm{S}}\right)$ because $T_{\mathrm{V}}$ and $T_{\mathrm{S}}$ are in a state of approximate heat balance for satellite (such as SMAP) local transit times of 6:00 a.m. and 18:00 p.m. Under these two assumptions, we can obtain surface emissivity (e) from Equation (1):

$$
e=(1-\omega)\left(1-t_{\mathrm{v}}\right)+(1-\omega)\left(1-t_{\mathrm{v}}\right) R_{\mathrm{s}} t_{\mathrm{v}}+\left(1-R_{\mathrm{s}}\right) t_{\mathrm{v}}
$$

where the meaning of each symbol of Equation (2) is the same as that of Equation (1).

\subsubsection{Change Detection Algorithm Derivation}

The change detection algorithm concept came from radar remote sensing and its theoretical basis was the linear relationship between the relative change of the backscatter coefficient and relative SSM change [8]. Many studies have estimated SSM from radar data based on the change detection algorithm $[9,10,23]$.

Here, we discuss the feasibility, problems, and potential of the algorithm's application in passive microwave remote sensing. First, we analyzed whether there is a linear relationship between the relative SSM change and relative change in surface emissivity. Second, we derived the specific expression of this method. According to the algorithm used in radar remote sensing, the corresponding formula for passive microwave remote sensing for a vegetated soil surface can be written as:

$$
\frac{\mathrm{SSM}-\mathrm{SSM}_{\mathrm{MAX}}}{\mathrm{SSM}_{\mathrm{MIN}}-\mathrm{SSM}_{\mathrm{MAX}}}=\frac{e-e_{\mathrm{MIN}}}{e_{\mathrm{MAX}}-e_{\mathrm{MIN}}}
$$


values. $e$ is the surface emissivity of vegetated soil defined by Equation (2), and $e_{\mathrm{MIN}}$ and $e_{\mathrm{MAX}}$ are the minimum and maximum values of $e$. Equation (3) determines the feasibility of the change 
detection algorithm based on passive microwave remote sensing. To verify this, taking Equation (2) into Equation (3) and simplifying, we obtain:

$$
\frac{\mathrm{SSM}-\mathrm{SSM}_{\mathrm{MAX}}}{\mathrm{SSM}_{\mathrm{MIN}}-\mathrm{SSM}_{\mathrm{MAX}}}=\frac{r-r_{\mathrm{MAX}}}{r_{\mathrm{MIN}}-r_{\mathrm{MAX}}}
$$

Here, $r$ is soil surface reflectivity, and $r_{\text {MIN }}$ and $r_{\text {MAX }}$ are the minimum and maximum values of $r$. Next, we needed to verify the applicability of Equation (4). We used the I2EM model [24] to simulate the surface reflectivity $(r)$ under different surface roughness (surface correlation length $(c l)=10 \mathrm{~cm}$, surface root mean square height $(\mathrm{s})=0.5 \mathrm{~cm}, 1 \mathrm{~cm}, 2 \mathrm{~cm}$ and $3 \mathrm{~cm})$ and soil moisture $\left(\mathrm{SSM}=0.05 \sim 0.35 \mathrm{~cm}^{3} / \mathrm{cm}^{3}\right.$ with $0.01 \mathrm{~cm}^{3} / \mathrm{cm}^{3}$ interval) conditions, the Mironov model [25] was used to calculate the complex dielectric constant of wet soil and the incidence angle was fixed at $40^{\circ}$. Figure 2 shows the relationship between the relative change of surface reflectivity and SSM, and indicates that the linear relationship given by Equation (4) was basically correct for both polarizations (horizontal and vertical) and various surface roughness conditions.



(a)



(b)

Figure 2. The relationship between the relative change of SSM (RC_SSM) and surface reflectivity (RC_e) for horizontal (a) and vertical (b) polarization for various surface roughness conditions $(\mathrm{cl}=10 \mathrm{~cm}$, $\mathrm{s}=0.5 \mathrm{~cm}, 1 \mathrm{~cm}, 2 \mathrm{~cm}$ and $3 \mathrm{~cm})$.

Because the change detection algorithm based on passive microwave remote sensing emissivity is feasible for estimating SSM, the SSM estimation expression must be derived from Equation (3) and can be written as:

$$
\mathrm{SSM}=\frac{e-e_{\mathrm{MIN}}}{e_{\mathrm{MAX}}-e_{\mathrm{MIN}}}\left(\mathrm{SSM}_{\mathrm{MIN}}-\mathrm{SSM}_{\mathrm{MAX}}\right)+\mathrm{SSM}_{\mathrm{MAX}}
$$

Equation (5) shows that values for minimum emissivity $\left(e_{\mathrm{MIN}}\right)$ and the difference between the minimum and maximum emissivity $\left(e_{\mathrm{MAX}}-e_{\mathrm{MIN}}\right)$ must be determined prior to estimating SSM. Values of $e_{\mathrm{MIN}}$ and $e_{\mathrm{MAX}}-e_{\mathrm{MIN}}$ are affected by vegetation type, VWC, surface roughness, soil texture, and topography. The pixel-based change detection algorithm assumes that roughness, soil texture and terrain are time invariant for a fixed pixel [23]. Therefore, we only considered vegetation change when solving for $e_{\mathrm{MIN}}$ and $e_{\mathrm{MAX}}-e_{\mathrm{MIN}}$.

\subsubsection{Determining Maximum and Minimum Surface Emissivity}

Assuming that surface roughness, texture and topography remain constant, surface emissivity is mainly affected by SSM and vegetation. Using the basic theory of microwave remote sensing, $e_{\mathrm{MIN}}$ for bare soil was obtained for the maximum SSM, and the maximum emissivity was obtained for the minimum SSM. Vegetated soil surface emissivity is also related to vegetation parameters (such as $\mathrm{VWC})$, and $e_{\mathrm{MIN}}$ and $e_{\mathrm{MAX}}-e_{\mathrm{MIN}}$ were determined according to statistics for VWC. TB, $T_{\mathrm{S}}, \mathrm{VWC}$, and SSM from the SMAP L3 product were used. To eliminate outliers, we segmented VWC at $0.5 \mathrm{~kg} / \mathrm{m}^{2}$ 
intervals and calculated the cumulative probability density distribution for each VWC segment, taking the value at the position where the cumulative probability distribution was $1 \%$ as the minimum emissivity. Figures 3 and 4 show the relationships between $e_{\mathrm{MIN}}$ and VWC for SMAP ascending and descending orbits respectively. This demonstrated that $e_{\mathrm{MIN}}$ was obtained for the maximum SSM for $\mathrm{H}$ polarization, $\mathrm{V}$ polarization, and combined $\mathrm{H}$ and $\mathrm{V}$ polarizations, and that $e_{\mathrm{MIN}}$ increased with VWC. This was because the increased emissivity from the vegetation canopy was greater than decreased emissivity of the soil surface attenuated by the canopy. In addition, there was a good linear relationship between $e_{\mathrm{MIN}}$ and VWC, indicated by higher $R^{2}[0.79,0.97]$ (Table 1 ). This showed that $e_{\text {MIN }}$ could be predicted by VWC.

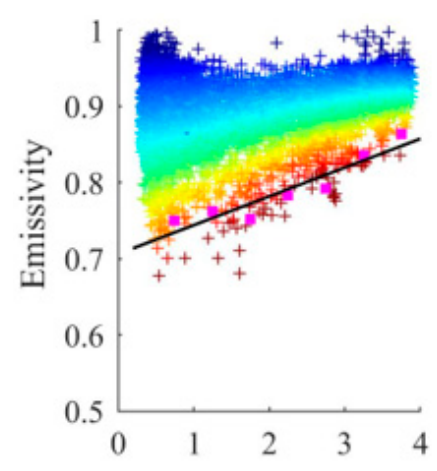

(a)

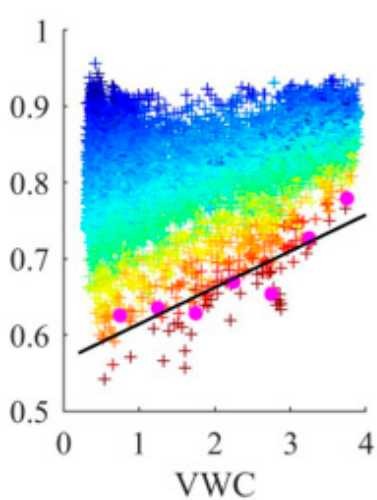

(b)

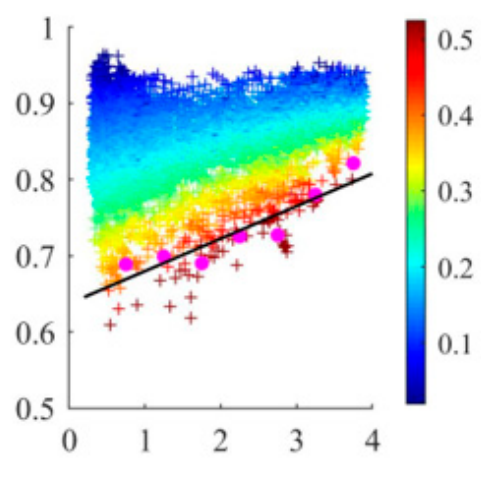

(c)

Figure 3. Minimum surface emissivity for vertical (a), horizontal (b) and combined vertical and horizontal (c) polarization at different VWC levels based on the ascending SMAP dataset. The color of ' + ' indicates the change in SSM. The pink circles represent $e_{\mathrm{MIN}}$ calculated for each VWC interval. The black solid line is the fitted linear relationship between $e_{\mathrm{MIN}}$ and VWC.

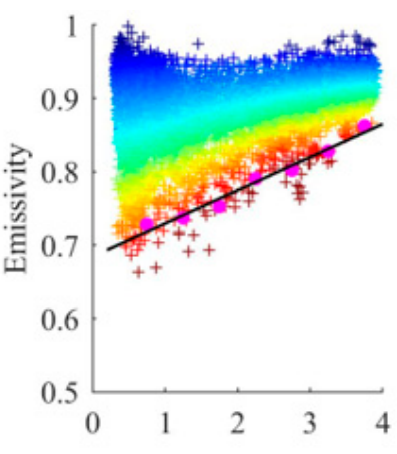

(a)



(b)



(c)

Figure 4. Minimum surface emissivity for vertical (a), horizontal (b) and combined vertical and horizontal (c) polarization at different VWC levels based on the descending SMAP dataset. The color of ' + ' indicates the change in SSM. The pink circles represent $e_{\mathrm{MIN}}$ calculated for each VWC interval. The black solid line is the fitted linear relationship between $e_{\mathrm{MIN}}$ and VWC.

There are two methods for calculating $\left.e_{\mathrm{MAX}}-e_{\mathrm{MIN}}: 1\right)$ Calculate $e_{\mathrm{MAX}}$ according to the VWC segment in the same way as $e_{\mathrm{MIN}}$, and obtain the difference $e_{\mathrm{MAX}}-e_{\mathrm{MIN}}$; 2 ) Calculate the difference between $e$ and $e_{\mathrm{MIN}}$ and then compute the maximum value of $\mathrm{e}-e_{\mathrm{MIN}}$, i.e., the value of $e_{\mathrm{MAX}}-e_{\mathrm{MIN}}$. In this study, the second method was adopted. Similarly, we took the value of the $99 \%$ cumulative probability distribution function as the value of $e_{\mathrm{MAX}}-e_{\mathrm{MIN}}$ to exclude outliers. The relationship between $e_{\mathrm{MAX}}-e_{\mathrm{MIN}}$ and VWC is shown in Figures 5 and 6 . This showed that $e_{\mathrm{MAX}}-e_{\mathrm{MIN}}$ values appeared when SSM is the direst for the same VWC. In contrast to $e_{\mathrm{MIN}}$, the value of $e_{\mathrm{MAX}}-e_{\mathrm{MIN}}$ decreased as VWC increased. A good linear relationship between $e_{\mathrm{MAX}}-e_{\mathrm{MIN}}$ and VWC was also 
indicated by higher $R^{2}[0.86,0.99]$ (Table 1$)$. This showed that the value of $e_{\mathrm{MAX}}-e_{\mathrm{MIN}}$ can be predicted by VWC.

Table 1. Fitted linear relationships between VWC and $e_{\mathrm{MIN}}\left(e_{\mathrm{MAX}}-e_{\mathrm{MIN}}\right)$, and corresponding fitted parameters $\left(R^{2}\right.$, RMSE_-root mean squared error) derived from SMAP ascending and descending L3 SSM datasets for an agricultural area in northeast China from 2016-2018.

\begin{tabular}{cccccccccc}
\hline \multirow{2}{*}{ Orbit } & \multirow{2}{*}{ Pol. } & Slope & Intercept & $\boldsymbol{R}^{\mathbf{2}}$ & $\boldsymbol{R}$ MSE & Slope & Intercept & $\boldsymbol{R}^{\mathbf{2}}$ & $\boldsymbol{R}$ MSE \\
\hline \multirow{4}{*}{ A } & $\mathrm{ev}$ & 0.03784 & 0.7062 & 0.87 & 0.019 & -0.03316 & 0.2501 & 0.86 & 0.015 \\
& $\mathrm{eh}$ & 0.0478 & 0.5665 & 0.79 & 0.029 & -0.04048 & 0.3363 & 0.97 & 0.008 \\
& $0.5(\mathrm{eh}+\mathrm{ev})$ & 0.04265 & 0.6372 & 0.84 & 0.021 & -0.03894 & 0.2925 & 0.97 & 0.007 \\
\hline \multirow{3}{*}{$\mathrm{D}$} & $\mathrm{ev}$ & 0.04524 & 0.6842 & 0.97 & 0.008 & -0.03854 & 0.2637 & 0.96 & 0.009 \\
& $\mathrm{eh}$ & 0.05509 & 0.5454 & 0.88 & 0.024 & -0.04746 & 0.3514 & 0.99 & 0.005 \\
& $0.5(\mathrm{eh}+\mathrm{ev})$ & 0.04842 & 0.6208 & 0.94 & 0.014 & -0.04359 & 0.3054 & 0.99 & 0.004 \\
\hline
\end{tabular}

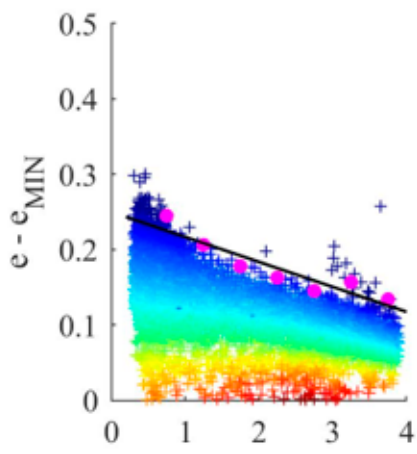

(a)

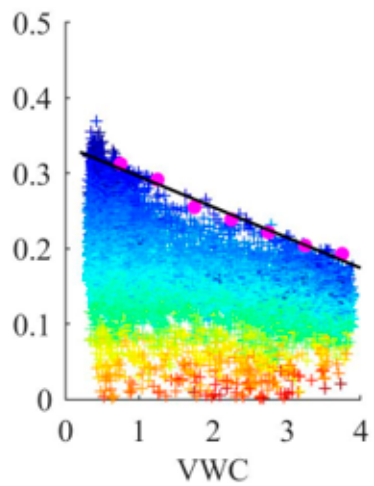

(b)

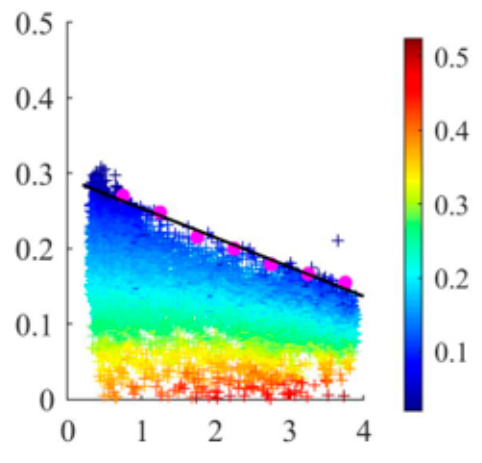

(c)

Figure 5. Difference between maximum and minimum of surface emissivity for vertical (a), horizontal (b) and combined vertical and horizontal (c) polarization at different VWC levels based on the ascending SMAP dataset. The color of ' + ' indicates the change of SSM. The pink circles represent $e_{\mathrm{MAX}}-e_{\mathrm{MIN}}$ calculated by each VWC interval. The black solid line is the fitted linear relationship between $e_{\text {MAX }}-e_{\text {MIN }}$ and VWC.



(a)

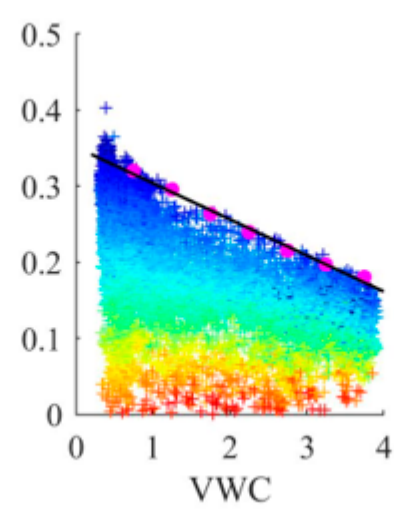

(b)



(c)

Figure 6. Difference between maximum and minimum of surface emissivity for vertical (a), horizontal (b) and combined vertical and horizontal (c) polarization at different VWC levels based on the descending SMAP dataset. The color of ' + ' indicates the change of SSM. The pink circles represent $e_{\mathrm{MAX}}-e_{\mathrm{MIN}}$ calculated by each VWC interval. The black solid line is the fitted linear relationship between $e_{\mathrm{MAX}}-e_{\mathrm{MIN}}$ and VWC. 
Once $e_{\mathrm{MIN}}$ and $e_{\mathrm{MAX}}-e_{\mathrm{MIN}}$ were determined, $\mathrm{SSM}_{\mathrm{MAX}}$ and $\mathrm{SSM}_{\mathrm{MIN}}$ were calculated and SSM was estimated. Here, SSM $_{\text {MAX }}$ and SSM $_{\text {MIN }}$ refer to the historical SSM maximum and minimum values for a single pixel. Therefore, their values can also be obtained by counting historical pixel values. To avoid the influence of extreme hydrological events (drought and flooding), 95\% of the maximum

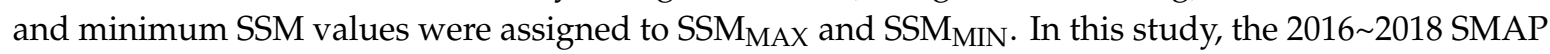
L3 SSM values were adopted to estimate SSM $\mathrm{MAX}$ and SSM $\mathrm{MIN}_{\mathrm{N}}$.

\section{Results}

\subsection{Comparison of SSM Derived from Change Detection Algorithm and SMAP L3 SSM}

Based on the brightness temperature and $T_{\mathrm{S}}$ in the SMAP L3 SSM dataset, the emissivity $(e)$ was derived, and $e_{\mathrm{MIN}}$ and $e_{\mathrm{MAX}}-e_{\mathrm{MIN}}$ was obtained from the VWC data in the SMAP L3 SSM dataset by the fitted linear relationship (Table 1). Then, we combine Equation (5) with the statistical extreme value of SSM (SSM MIN $_{\text {and }}$ SSM $\left.M_{M A X}\right)$ to derive SSM $\left(S_{\text {DCA }}\right)$ based on the change detection algorithm. Figure 7 compares SMAP L3 SSM and SSM ${ }_{\text {DCA }}$ for ascending orbit, and Figure 8 shows the same

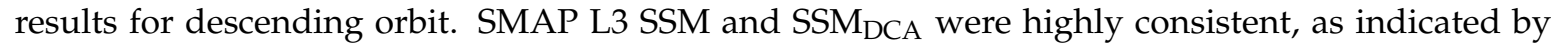
high $R^{2}$ and low RMSE values (Table 2). Similar SSM ${ }_{\mathrm{DCA}}$ accuracy was achieved for both ascending and descending orbits, while little difference accuracy was found for various polarizations. SSM $\mathrm{DCA}_{\mathrm{D}}$ accuracy was the highest for $\mathrm{V}$ polarization, followed by combined $\mathrm{H}$ and $\mathrm{V}$ polarization, and finally $\mathrm{H}$ polarization (Table 2). This result corresponded to the simulation results in Figure 2, so the linear relationship between relative SSM change and relative emissivity change was better for V polarization than $\mathrm{H}$ polarization.

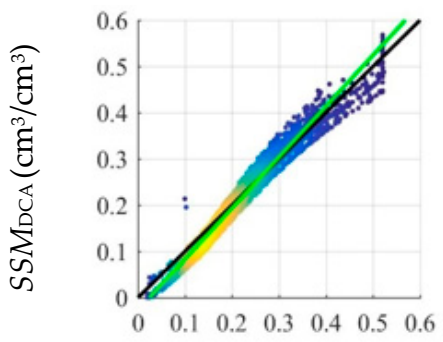

(a)

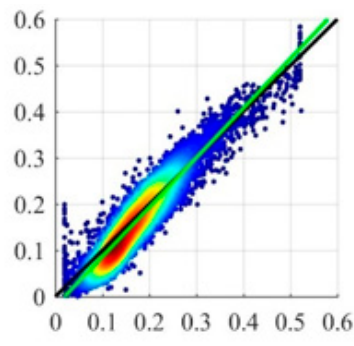

SMAP L3 SSM $\left(\mathrm{cm}^{3} / \mathrm{cm}^{3}\right)$

(b)



(c)

Figure 7. Comparison of SSM retrieved from the change detection algorithm $\left(S_{D S} M_{D C A}\right)$ developed in this study and SMAP L3 SSM for V (a), $\mathrm{H}(\mathbf{b})$ and $0.5(\mathrm{H}+\mathrm{V})(\mathbf{c})$ polarization for ascending orbit ( $N=6631$ ) from 2016-2018. The color of the colorbar indicates the point density of SSM $\mathrm{DCA}$ and SMAP L3 SSM.

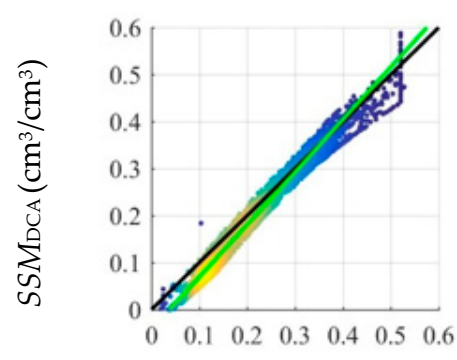

(a)

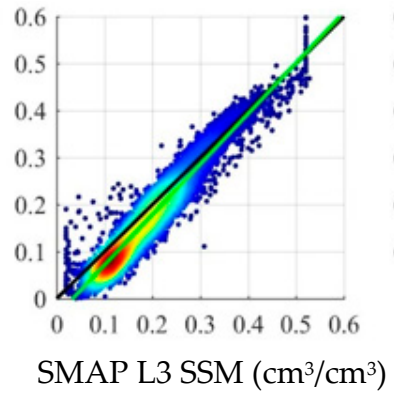

(b)



(c)

Figure 8. Comparison of SSM retrieved from the change detection algorithm $\left(S_{S S M} M_{D C}\right)$ developed in this study and SMAP L3 SSM for $\mathrm{V}(\mathbf{a}), \mathrm{H}(\mathbf{b})$ and $0.5(\mathrm{H}+\mathrm{V})(\mathbf{c})$ polarization for descending orbit $(\mathrm{N}=6631)$ from $2016-2018$. The color of the colorbar indicates the point density of SSM ${ }_{\mathrm{DCA}}$ and SMAP L3 SSM. 
Table 2. The fitted coefficient and statistical error of SMAP L3 SSM and estimated SSM from SMAP L3 dataset based on the change detection algorithm developed here.

\begin{tabular}{cccccc}
\hline Orbit & Polarization & $\boldsymbol{a}$ & $\boldsymbol{b}$ & $\boldsymbol{R}^{\mathbf{2}}$ & $\boldsymbol{R}$ MSE \\
\hline \multirow{3}{*}{$\mathrm{A}$} & ev & 1.102 & -0.02666 & 0.96 & 0.016 \\
& $\mathrm{eh}$ & 1.071 & -0.02079 & 0.89 & 0.031 \\
& $0.5(\mathrm{eh}+\mathrm{ev})$ & 1.089 & -0.02842 & 0.93 & 0.023 \\
\hline \multirow{2}{*}{$\mathrm{D}$} & ev & 1.116 & -0.04217 & 0.97 & 0.015 \\
& eh & 1.074 & -0.03591 & 0.92 & 0.027 \\
& $0.5(\mathrm{eh}+\mathrm{ev})$ & 1.088 & -0.03662 & 0.96 & 0.019 \\
\hline
\end{tabular}

\subsection{Comparison of SSM Derived From Change Detection Algorithm and In Situ SSM}

After assessing the consistency between SSM $_{\mathrm{DCA}}$ and SMAP L3 SSM, it was necessary to further analyze the consistency between SSM $_{\mathrm{DCA}}$ and in situ SSM. Hourly point-scale in situ SSM values from the soil moisture observation network, closest to the satellite transit time, were up-scaled to the

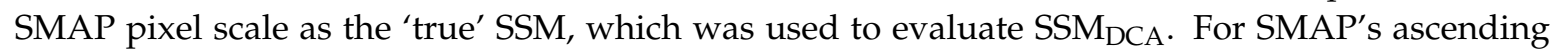
orbit, respective RMSE values were $0.045 \mathrm{~cm}^{3} / \mathrm{cm}^{3}, 0.052 \mathrm{~cm}^{3} / \mathrm{cm}^{3}, 0.038 \mathrm{~cm}^{3} / \mathrm{cm}^{3}, 0.042 \mathrm{~cm}^{3} / \mathrm{cm}^{3}$ for estimated SSM from SMAP L3, SMAP H pol TB, SMAP V pol TB, and combined H and V pol TB. The corresponding bias values were $0.024 \mathrm{~cm}^{3} / \mathrm{cm}^{3}, 0.026 \mathrm{~cm}^{3} / \mathrm{cm}^{3}, 0.0055 \mathrm{~cm}^{3} / \mathrm{cm}^{3}$ and $0.0125 \mathrm{~cm}^{3} / \mathrm{cm}^{3}$ (Figure 9). $\mathrm{SSM}_{\mathrm{DCA}}-\mathrm{V}$ performed better than the other three SSM results due to its low RMSE and bias. For SMAP's descending orbit, RMSE values were $0.050 \mathrm{~cm}^{3} / \mathrm{cm}^{3}, 0.056 \mathrm{~cm}^{3} / \mathrm{cm}^{3}, 0.051 \mathrm{~cm}^{3} / \mathrm{cm}^{3}$, $0.049 \mathrm{~cm}^{3} / \mathrm{cm}^{3}$ for estimated SSM from SMAP L3, SMAP H pol TB, SMAP V pol TB, and combined $\mathrm{H}$ and $\mathrm{V}$ pol TB. The corresponding bias values were $0.012 \mathrm{~cm}^{3} / \mathrm{cm}^{3}, 0.023 \mathrm{~cm}^{3} / \mathrm{cm}^{3},-0.003 \mathrm{~cm}^{3} / \mathrm{cm}^{3}$ and $0.006 \mathrm{~cm}^{3} / \mathrm{cm}^{3}$ (Figure 10). SSM $\mathrm{DCA}-\mathrm{VH}$ performance was better than the other three SSM results. However, the correlation coefficient between SMAP L3 SSM and in situ SSM was higher than all three $S_{S S M}$ DCA results. This showed that compared with in situ SSM, SSM ${ }_{D C A}$ accuracy was equivalent to or better than the SMAP algorithm. Possible reasons for this will be analyzed in the next section.



(a)

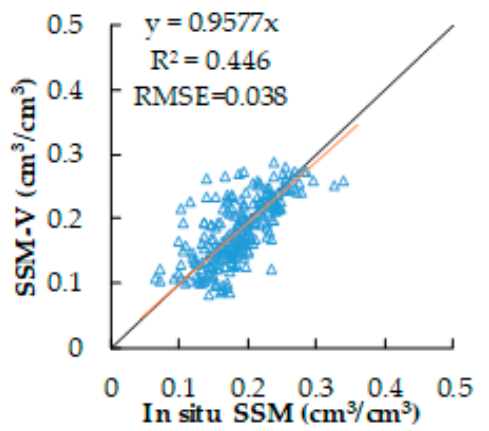

(c)

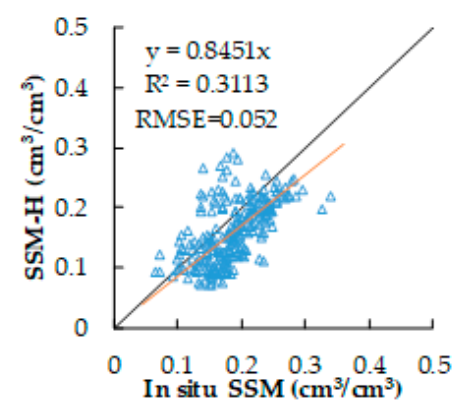

(b)

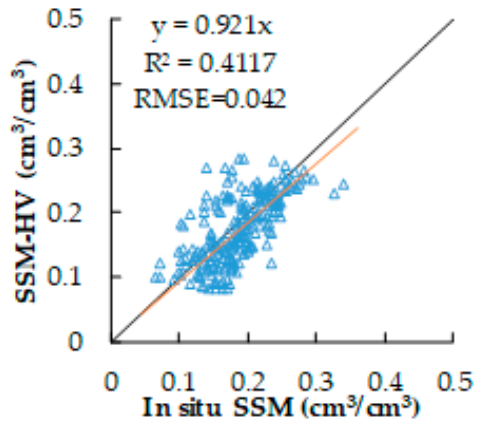

(d)

Figure 9. Comparison of in situ SSM values $\left(\mathrm{cm}^{3} / \mathrm{cm}^{3}\right)$ and retrieved SSM values $\left(\mathrm{cm}^{3} / \mathrm{cm}^{3}\right)$ for ascending orbit from 2016-2018. (a) SMAP L3, (b) $\mathrm{H} \mathrm{pol}$, (c) $\mathrm{V}$ pol, (d) 0.5(H + V). The black line is the 1:1 line and the brown line is the fitted linear equation. 


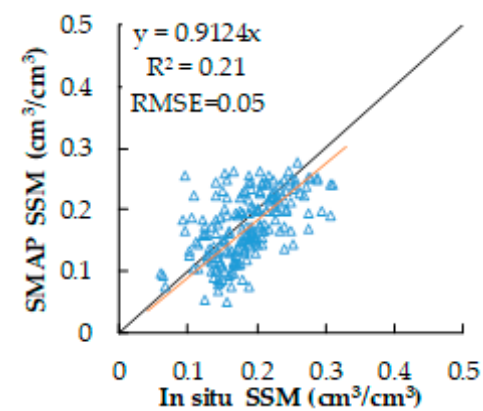

(a)

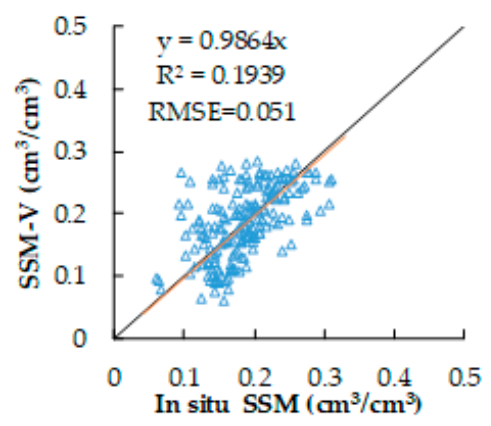

(c)

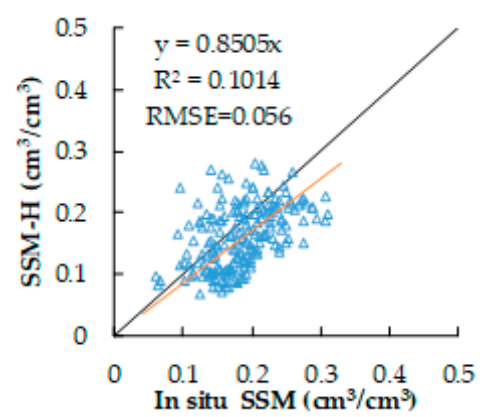

(b)



(d)

Figure 10. Comparison of in situ SSM values $\left(\mathrm{cm}^{3} / \mathrm{cm}^{3}\right)$ and retrieved SSM values $\left(\mathrm{cm}^{3} / \mathrm{cm}^{3}\right)$ for descending orbit from 2016-2018. (a) SMAP L3, (b) H pol, (c) V pol, (d) 0.5(H + V). The black line is the 1:1 line and the brown line is the fitted linear equation.

\section{Discussion}

\subsection{Temporal Distribution of SSM Error}

Comparing the temporal distribution of SSM error can support analysis of the error sources of different SSM algorithms. We compared the errors from four SSM results (SMAP L3 SSM and three SSM results estimated from different SMAP data polarizations based on the change detection algorithm). For ascending orbit, the SSM bias results indicated that SSM was underestimated for May and July, and overestimated for August and September (Figure 11). High RMSE and ubRMSE values occurred in June and low values occurred in September. For descending orbit, there was no clear seasonal change in bias, RMSE, or ubRMSE (Figure 12). The SSM bias estimated from SMAP H polarization TB increased overtime. Both RMSE and ubRMSE were about $0.05 \mathrm{~cm}^{3} / \mathrm{cm}^{3}$ over the study period, with slightly lower values in May and September and higher values during the other three months.

Generally, the temporal distributions of SSM error for three change detection algorithms were similar to the SMAP L3 SSM error. The SSM bias estimated from the combined TB of H and V polarizations was close to SMAP SSM, while RMSE and ubRMSE values for SSM estimated from the $\mathrm{TB}$ at $\mathrm{V}$ polarization was closer to SMAP SSM.

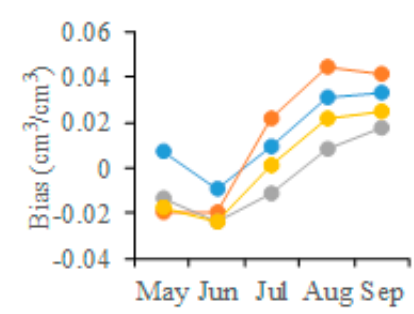

(a)

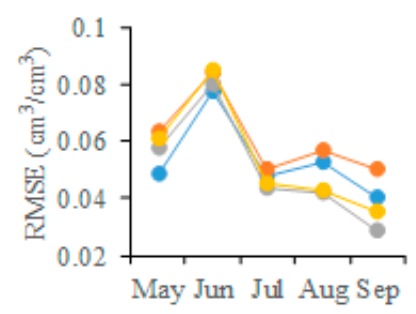

(b)

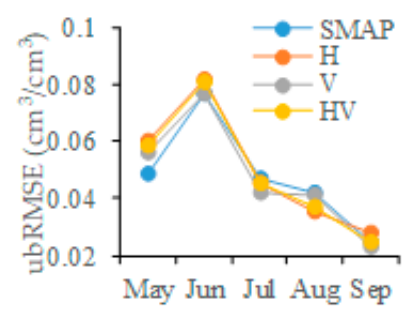

(c)

Figure 11. Change in average monthly bias, RMSE and ubRMSE of estimated SSM for four algorithms with time, based on the SMAP ascending brightness temperature from 2016-2018. 


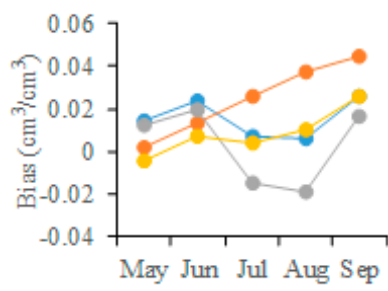

(a)



(b)

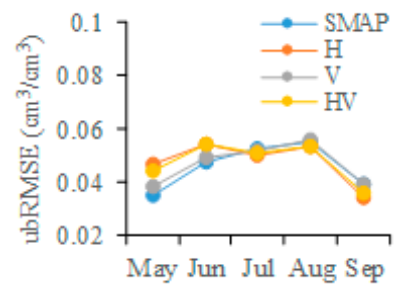

(c)

Figure 12. (a) Monthly bias, (b) RMSE and (c) ubRMSE of estimated SSM from the 2016-2018 SMAP descending brightness temperature based on the four algorithms (SMAP baseline, DCA-H, DCA-V and DCA-HV)

\subsection{Dependence of Bias on SSM Algorithm Input Parameters}

To further analyze the SSM bias sources, we analyzed the relationship between SSM bias and the SSM algorithm input parameters. Because the four error results were similar, the $V$ polarization SSM result that was the closest to SMAP L3 SSM was selected for this analysis. Figure 13 shows the dependence of SSM bias on $T_{\mathrm{S}}$, VWC, and surface emissivity for ascending and descending orbits. SSM bias on days when rainfall exceeded $10 \mathrm{~mm}$ is indicated by a "+", and a high bias was observed on those days. There was no clear dependence of bias on $T_{\mathrm{S}}$ and VWC, as opposed to surface emissivity. Except for rainfall events, a negative bias occurred for relatively low surface emissivity and a positive bias occurred under high surface emissivity (Figure 13). This meant that the algorithm overestimated SSM for wet soils and underestimated it for dry soils. SSM MAX and SSM $_{\text {MIN }}$ values may be problematic because only three years of data were used in this study. It may also be related to the uncertainty of VWC used in the SMAP algorithm. In this study area, the highest VWC value was about $4 \mathrm{~kg} / \mathrm{m}^{2}$ in the SMAP algorithm, lower than the actual maximum (close to $10 \mathrm{~kg} / \mathrm{m}^{2}$ ) [26]. Underestimated VWC may have overstated the soil contribution to total brightness temperature in the SSM algorithm, leading to the underestimation of SSM.
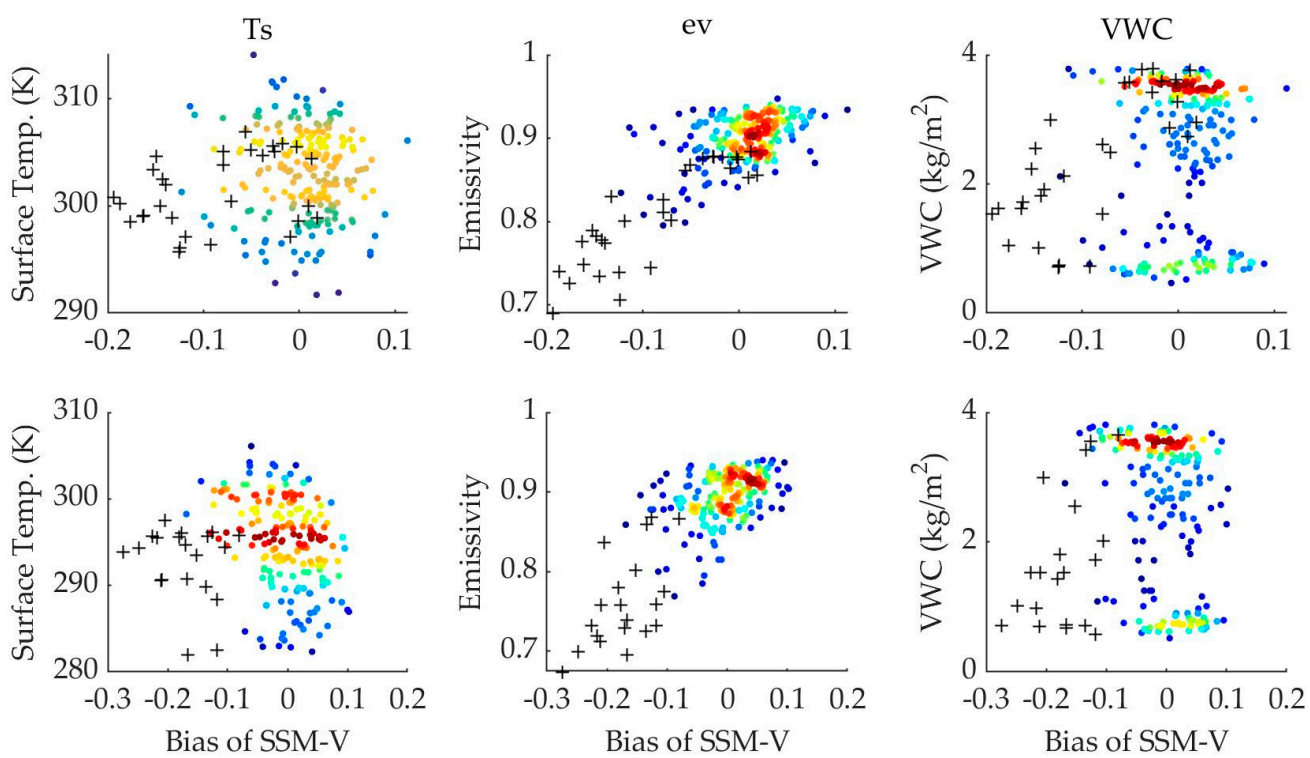

Figure 13. Dependence of SSM bias on inversion model input parameters from 2016-2018. The above three figures show results for ascending orbit and the bottom three figures show results for descending orbit. The cross symbol "+" indicates that daily rainfall exceeded $10 \mathrm{~mm}$ and the color of the data point indicates the density. 


\subsection{Limitations, Advantages, and Potential for SSM Estimation Using the Change Detection Algorithm}

The change detection algorithm is based on the principle of surface microwave radiation and belongs to the semi-empirical algorithm. Its advantage lies in its simplicity. On the other hand, the challenge is to reliably estimate $\mathrm{e}_{\mathrm{MAX}}$ (and $\mathrm{e}_{\mathrm{MIN}}$ ) and $S S M_{\mathrm{MAX}}$ (and $S S M_{\mathrm{MIN}}$ ). The vegetated surface emissivity is affected by SSM, surface roughness, VWC and canopy structure, soil texture, soil organic matter, land cover type, topography, heterogeneity, and other factors. The change detection algorithm can reduce the influence of time invariant variables at the pixel-scale (such as soil texture, organic matter, topography, land cover, and roughness) on the accuracy of retrieved SSM. The effects of time-varying variables (such as canopy properties) are parameterized by VWC (or NDVI). SSM MAX and $S S M_{\mathrm{MIN}}$ values for a pixel are related to dry and wet climate zones. Therefore, $S S M_{\mathrm{MAX}}$ and $S S M_{\text {MIN }}$ may differ across climate zones. The existing SSM values need to be used to train $S S M_{M A X}$ and $S S M_{M I N}$. Therefore, a longer SSM data time series leads to higher algorithm stability.

Similar to SMAP, surface roughness is assumed to be a constant that does not change with time in the change detection algorithm. In fact, surface roughness changes with human activities associated with farming activities and rainfall. The change detection algorithm can eliminate the influence of incoherent radiation caused by changing surface roughness to a certain extent, using combined polarized brightness temperature. However, performance in practical applications is not very good and the effect of surface roughness on this algorithm needs to be further explored.

The reason why VWC is used to establish the relationship with SMAP emissivity in this study is that the differences of vegetation types are taken into account in the calculation of VWC based on NDVI. It means that the same NDVI may correspond to different VWC for different vegetation types. The attenuation of the incident electromagnetic wave and self-radiation of the vegetation canopy mainly depend on its VWC and structure. Although VWC is estimated based on NDVI, this study uses VWC to establish the relationship, mainly to reduce the modeling error of vegetation attenuation and self-radiation ability under different vegetation types.

\section{Conclusions}

This work was carried out to verify the feasibility of the change detection algorithm for estimating SSM from L-band passive microwave $T B$, and can be divided into two aspects: theoretical simulation based on the radiative transfer model and validation based on in situ soil moisture. The following conclusions were obtained:

(1) Based on the simulated L-band reflectivity of bare soil under different conditions (surface roughness, SSM), there was an approximate linear relationship between the SSM and surface emissivity with $\mathrm{R}^{2}>0.98$ for both $\mathrm{H}$ and $\mathrm{V}$ polarization. This meant that the change detection algorithm could be used to estimate SSM from passive microwave TB.

(2) Time-series values for TB, $T_{\mathrm{S}}$, VWC and SSM provided by SMAP L3 dataset were used to calculate the minimum emissivity $\left(\mathrm{e}_{\mathrm{MIN}}\right)$ and $\mathrm{e}_{\mathrm{MAX}}-\mathrm{e}_{\mathrm{MIN}}$ for each VWC interval, and a linear relationship between them was developed for ascending and descending orbits. This was applied in the change detection algorithm.

(3) SSM values estimated by the change detection algorithm were in good agreement with SMAP L3 SSM and up-scaled in situ SSM from the soil moisture observation network. This showed that the algorithm can be used to estimate SSM in China's northeastern farmland area. The SSM estimation accuracy of $\mathrm{V}$ polarization $T B$ was higher than $\mathrm{H}$ polarization and combined $\mathrm{H}$ and $\mathrm{V}$ polarization.

(4) The temporal distribution of SSM error (bias, RMSE and ubRMSE) estimated by the change detection algorithm was very similar to SMAP L3 SSM. This may be because $e_{\mathrm{MIN}}$ and the maximum value of $e-e_{\mathrm{MIN}}$ (also for $S S M_{\mathrm{MIN}}$ and $S S M_{\mathrm{MAX}}$ ) in the algorithm were trained according to SMAP L3 SSM.

Although this study confirmed the feasibility of using the change detection algorithm for SSM estimation based on passive microwave remote sensing, the sources and characteristics of errors need to be further analyzed. It should also be validated for other land cover types and at larger spatial scales. 
Author Contributions: Conceptualization, X.Z.; methodology, B.L.; validation, L.L.; formal analysis, T.J.; resources, X.X.; data curation, H.X. and Y.S.; writing-original draft preparation, Z.F.; writing-review and editing, X.L. (Xiaofeng Li); visualization, X.L. (Xiaojie Li). All authors have read and agreed to the published version of the manuscript.

Funding: This research was funded by the NATIONAL NATURAL SCIENCE FOUNDATION OF CHINA, grant number 41971323.

Acknowledgments: Thanks NSIDC for providing the SMAP L3 dataset.

Conflicts of Interest: The authors declare no conflict of interest.

\section{References}

1. Magagi, R.; Berg, A.A.; Goita, K.; Belair, S.; Jackson, T.J.; Toth, B.; Walker, A.; Mcnairn, H.; O'Neill, P.E.; Moghaddam, M. Canadian Experiment for Soil Moisture in 2010 (CanEx-SM10): Overview and Preliminary Results. IEEE Trans. Geosci. Remote Sens. 2012, 51, 347-363. [CrossRef]

2. Shi, J.C.; Yang, D.; Du, J.Y.; Jiang, L.M.; Chai, L.N.; Mao, K.B.; Peng, X.; Ni, W.J.; Xiong, C.; Qiang, L. Progresses on microwave remote sensing of land surface parameters. J. Sci. China Earth Sci. 2012, 55, 1052-1078. [CrossRef]

3. Entekhabi, D.; Njoku, E.G.;O’Neill, P.E.; Kellogg, K.H.; Crow, W.T.; Edelstein, W.N.; Entin, J.K.; Goodman, S.D.; Jackson, T.J.; Johnson, J.; et al. The Soil Moisture Active Passive (SMAP) Mission. Proc. IEEE 2010, 98, 704-716. [CrossRef]

4. Kerr, Y.H.; Waldteufel, P.; Wigneron, J.P.; Delwart, S.; Cabot, F.; Boutin, J.; Escorihuela, M.J.; Font, J.; Reul, N.; Gruhier, C.; et al. The SMOS Mission: New Tool for Monitoring Key Elements ofthe Global Water Cycle. Proc. IEEE 2010, 98, 666-687. [CrossRef]

5. Bazzi, H.; Baghdadi, N.; El Hajj, M.; Zribi, M.; Belhouchette, H. A Comparison of Two Soil Moisture Products S2MP and Copernicus-SSM over Southern France. J. Sel. Top. Appl. Earth Obs. Remote Sens. 2019, 12, 3366-3375. [CrossRef]

6. Kerr, Y.H.; Waldteufel, P.; Wigneron, J.P.; Martinuzzi, J.; Font, J.; Berger, M. Soil moisture retrieval from space: The Soil Moisture and Ocean Salinity (SMOS) mission. IEEE Trans. Geosci. Remote Sens. 2002, 39, 1729-1735. [CrossRef]

7. Wigneron, J.-P.; Jackson, T.J.; O’Neill, P.; De Lannoy, G.; Rosnay, P.; Walker, J.P.; Ferrazzoli, P.; Mironov, V.; Bircher, S.; Grant, J.P.; et al. Modelling the passive microwave signature from land surfaces: A review of recent results and application to the L-band SMOS \& SMAP soil moisture retrieval algorithms. Remote Sens. Environ. 2017, 192, 238-262.

8. Wagner, W.; Lemoine, G.; Borgeaud, M.; Rott, H. A study of vegetation cover effects on ERS scatterometer data. IEEE Trans. Geosci. Remote Sens. 1999, 37, 938-948. [CrossRef]

9. Srivastava, H.S.; Patel, P.; Sharma, Y. Large-area soil moisture estimation using multi-incidence-angle RADARSAT-1 SAR data. IEEE Trans. Geosci. Remote Sens. 2009, 47, 2528-2535. [CrossRef]

10. Baghdadi, N.; Aubert, M.; Cerdan, O.; Franchistéguy, L.; Viel, C.; Eric, M.; Zribi, M.; Desprats, J.F. Operational Mapping of Soil Moisture Using Synthetic Aperture Radar Data: Application to the Touch Basin (France). Sensors 2007, 7, 2458-2483. [CrossRef]

11. Zheng, X.M.; Bai, Y.; Jiang, T.; Zhao, X.W.; Yang, J.W. Evaluation of SMAP Passive Soil Moisture Products using in-situ data from a dense observation network over Agricultural Area in Northeast China. IEEE Int. Geosci. Remote Sens. Symp. 2018, 3779-3882. [CrossRef]

12. Colliander, A.; Jackson, T.J.; Bindlish, J.R.; Chan, S.; Das, N.; Kim, S.B.; Cosh, M.H.; Dunbar, R.S.; Dang, L.; Pashaian, L.; et al. Validation of SMAP surface soil moisture products with core validation sites. Remote Sens. Environ. 2017, 191, 215-231. [CrossRef]

13. O'Neill, P.E.; Chan, S.; Njoku, E.G.; Jackson, T.; Bindlish, R. SMAP L3 Radiometer Global Daily 36 km EASE-Grid Soil Moisture, Version 6. Boulder, Colorado USA. NASA National Snow and Ice Data Center Distributed Active Archive Center. In Proceedings of the 2019 Photonics \& Electromagnetics Research Symposium-Fall (PIERS-Fall), Xiamen, China, 17-20 December 2019. [CrossRef] 
14. O'Neill, P.E.; Bindlish, R.; Chan, S.; Chaubell, J.; Njoku, E.G.; Jackson, T. Algorithm Theoretical Basis Document Level 2 \& 3 Soil Moisture (Passive) Data Products, Revision E, 2019b, JPL D-66480. Available online: https://nsidc.org/sites/nsidc.org/files/technical-references/L2_SM_P_ATBD_rev_E_Aug2019.pdf (accessed on 18 April 2020).

15. Le Vine, D.M.; Karam, M.A. Dependence of attenuation in a vegetation canopy on frequency and plant water content. IEEE Trans. Geosci. Remote Sens. 1996, 34, 1090-1096. [CrossRef]

16. Loew, A. Impact of surface heterogeneity on surface soil moisture retrievals from passive microwave data at the regional scale: The Upper Danube case. Remote Sens. Environ. 2008, 112, 231-248. [CrossRef]

17. Wigneron, J.P.; Calvet, J.C.; De Rosnay, P.; Kerr, Y.; Waldteufel, P.; Saleh, K.; Escorihuela, M.J.; Kruszewski, A. Soil moisture retrievals from biangular L-band passive microwave observations. IEEE Geosci. Remote Sens. Lett. 2004, 1, 277-281. [CrossRef]

18. Wigneron, J.P.; Kerr, Y.; Waldteufel, P.; Saleh, K.; Escorihuela, M.J.; Richaume, P.; Ferrazzoli, P.; De Rosnay, P.; Gurney, R.; Calvet, J.C.; et al. L-band microwave emission of the biosphere (L-MEB) model: Description and calibration against experimental data sets over crop fields. Remote Sens. Environ. 2007, 107, 639-655. [CrossRef]

19. Van de Griend, A.A.; Wigneron, J.P.; Waldteufel, P. Consequences of surface heterogeneity for parameter retrieval from 1.4-GHz multiangle SMOS observations. IEEE Trans. Geosci. Remote Sens. 2003, 41, 803-811. [CrossRef]

20. Wigneron, J.P.; Laguerre, L.; Kerr, Y.H. A simple parameterization of the L-band microwave emission from rough agricultural soils. IEEE Trans. Geosci. Remote Sens. 2001, 39, 1697-1707. [CrossRef]

21. Li, D.; Jin, R.; Che, T.; Walker, J.; Gao, Y.; Ye, N.; Wang, S. Soil moisture retrieval from airborne PLMR and MODIS products in the Zhangye oasis of middle stream of the Heihe River Basin, China. J. Adv. Earth Sci. 2014, 29, 295-305. [CrossRef]

22. Jiang, T.; Zhao, K.; Zheng, X.M.; Chen, S.; Wan, X.K. Dynamic bp in the L Band and Its Role in Improving the Accuracy of Soil Moisture Retrieval. J. Chin. Geogr. Sci. 2019, 29, 283-292. [CrossRef]

23. Attarzadeh, R.; Amini, J.; Notarnicola, C.; Greifeneder, F. Synergetic Use of Sentinel-1 and Sentinel-2 Data for Soil Moisture Mapping at Plot Scale. Remote Sens. 2018, 10, 1285. [CrossRef]

24. Ulaby, F.T.; Long, D.G. Microwave Radar and Radiometric Remote Sensing; University Michigan Press: Ann Arbor, MI, USA, 2014; p. 252. ISBN 978-0-472-11935-6.

25. Mironov, V.; Savin, I. A temperature-dependent multi-relaxation spectroscopic dielectric model for thawed and frozen organic soil at 0.05-15 GHz. Phys. Chem. Earth 2015, 83-84, 57-64. [CrossRef]

26. Zheng, X.M.; Ding, Y.L.; Zhao, X.W.; Bai, Y.; Li, X.F.; Zhao, K.; Jiang, T. Uncertainty evaluation at three spatial scales for the NDVI-based VWC estimation method used in the SMAP algorithm. Remote Sens. Lett. 2019, 10, 563-572. [CrossRef]

(C) 2020 by the authors. Licensee MDPI, Basel, Switzerland. This article is an open access article distributed under the terms and conditions of the Creative Commons Attribution (CC BY) license (http://creativecommons.org/licenses/by/4.0/). 